\title{
Taste receptors in the gastrointestinal system
}

\author{
Ana M San Gabriel
}

\begin{abstract}
In the last 15 years, advancements in molecular biology have unraveled the proteins that function as taste receptors. There are at least five taste qualities that are consciously perceived, sweet, sour, salty, bitter, and umami. Of these five, sour and salty are mediated by ion channels, whereas the perception of sweet, umami, and bitter tastes is mediated by G protein-coupled receptors (GPCRs). These taste GPCRs belong to the TAS1R and TAS2R gene families. There are other nutrient-binding GPCRs whose taste function is still being studied such as CaSR, GPRC6A, GPR92, or GPR120. It has been suspected for more than a century that the gut can sense the chemical composition of foods. The description of multiple taste GPCRs in gastrointestinal (Gl) cells suggests that there are nutrient-sensing mechanisms in the Gl tract, oral, gastric, and intestinal mucosa. Oral sensing seems to mainly influence food discrimination and nutrient appetite, while post-oral chemosensors may relate to nutrient utilization and inhibition of appetite. The most common accepted view is that taste GPCRs are present in enteroendocrine cells among others also known as chemosensory cells. These cells express taste receptors and other taste-related genes. Although, functional cells of the Gl mucosa that are not enteroendocrine or brush cells such as enterocytes or gastric cells may also hold receptive mechanisms that transduce the presence of certain nutrients in ingested foods and regulate gastric functions. This paper examines the importance of food chemical signals in their association with the neuroendocrine mechanisms they trigger, which are the core for metabolism and appetite regulation.
\end{abstract}

Keywords: Chemical sensing, Gut, Taste receptors, Vagus nerve, Peptide hormones, Umami, GPCRs, Cephalic phase

\section{Introduction}

Sugars, organic acids, minerals, alkaloids, or amino acids in foods bind to their corresponding taste receptors acting themselves as chemical messengers and inducing one of the known five taste qualities, sweet, sour, salty, bitter, and umami or savory taste, the taste of glutamate [1]. This interaction between single nutrients and taste receptors serves three basic purposes, to identify and discriminate foods and drinks, to promote or discourage ingestion, and to facilitate nutrient utilization by learned anticipatory or cephalic phase responses [2]. In his latest review, Alexander Bachmanov et al. describe taste receptors 'as one of the interfaces between internal and external milieus' [1]. Indeed, taste receptors appear to inform the brain of the chemical composition of foods and in turn, the brain responds accordingly with learned anticipatory responses to maintain body homeostasis prior to nutrient absorption [3]. Anticipatory responses that involved brain reflexes after sensory stimulation reduce the impact of food in our body. If taste receptors in the oral cavity are

Correspondence: sangabriel.umamiinfo@gmail.com Umami Information Centre, Tokyo 102-0084, Japan part of the conscious perception of the chemical composition of foods, it is not surprising that the same taste receptors from the oral cavity are also found in the gastrointestinal tract (GI). There, taste receptors also sense the chemical milieu of the luminal contents. But in the gut, the function of taste receptors is not to identify foods, rather to transduce the nutrient signal into neuropeptide hormones, vagus nerve activation, and nutrient utilization, all important modulators of digestive processes, appetite, and metabolism $[4,5]$.

\section{Taste, flavor, and gut chemical sensing}

Newborn infants have a strong innate liking for sweet and umami tastes while manifesting aversion for bitterness [5]. These inborn responses may predispose the infants for the acceptance of sweet and umami taste compounds present in breast milk [6,7]. It is not until they experience the volatile components of the flavor that infants learn to prefer or reject certain foods [8]. This learning process for flavor preference consists on classic Pavlovian conditioning reflexes from the post-oral nutritional effects of foods $[3,9]$. Flavor allows us to learn 
the association between foods and their metabolic and physiological outcome. This is especially important in human adults because we consumed a varied diet. By learning the relationship between the sensorial attributes of foods and their post-oral outcome, the brain can predict the physiological and metabolic impact that specific meals may have in our body [9]. The cephalic phase insulin release (CPIR) after glucose ingestion or the induction of salivary, gastric, and pancreatic secretions in response to a meal are good examples of conditioned physiological responses [3]. In fact, oral ingestion of glucose generates higher insulin release than a similar amount of glucose directly injected intravenously $[10,11]$. The higher insulin secretion after glucose ingestion most likely results from the strengthening of CPIR with the stimulation of sweet receptors in gut enteroendocrine cells that further enhance blood insulin via incretin hormones such as glucagon-like peptide 1 (GLP-1). The effect of glucose binding to sweet receptors in the gut goes as far as to increase the number of glucose transporters in enterocytes [12]. This oral and post-oral stimulation by glucose illustrates clearly that intestinal signals reinforce taste information allowing for more efficient physiological responses to meals in accordance to their chemical composition.

\section{Overview of taste receptors}

In the last decade, taste physiologists, geneticists, and molecular biologists have discovered that receptors for sweet, umami, and bitter tastes are members of the G protein-coupled receptor (GPCR) proteins [1]. Sweet and umami receptors belong to the T1R family, whereas bitter receptors are part of the T2R family $[13,14]$. The family of T1Rs is included in the class $\mathrm{C}$ group of protein (metabotropic glutamate/pheromone) receptors with three proteins, T1R1, T1R2, and T1R3. In humans, the combination of T1R2 with T1R3 functions as a sweet receptor. Many varied compounds taste sweet to humans, from sugar alcohols and glycosides to amino acids and proteins $[1,15,16]$. Receptors for umami result from the combination of T1R1 and T1R3, T1R3 being common for sweet and umami taste $[1,13,16]$. Compounds with a strong umami taste to humans comprise L-amino acids, such as glutamate and aspartate, and $5^{\prime}$-ribonucleotides [15]. Other substances with weaker umami attributes are theogallin, theanine, ibotenic, tricholomic, succinic, and gallic acids besides several peptides [1]. There is also evidence for considering as umami receptors splicing variants of metabotropic glutamate receptors types 1 and 4 (mGluR4 and mGluR1), which belong to the same family of T1Rs, and the N-methyl-D-aspartate (NMDA) glutamate ion channel receptor $[1,17,18]$. The perception of bitter taste that arouses innate aversive behavior includes a large variety of compounds, mostly toxic chemicals from plants or microorganisms. Bitter taste receptors belong to the T2Rs (taste receptor type 2) of the class A of GPCR family (rhodopsin like). Humans exhibit 25 TAS2R bitterreceptor genes among which 20 receptors have been already de-orphanized by using heterologous in vitro cell systems [19]. Some of these receptors are specific to a single or a few bitter compounds, whereas others are tuned to a wide variety of chemical compounds. For salty taste, after many years of conjecture, the epithelial sodium channel $(\mathrm{ENaC})$ was proved to be responsible for the transduction of salty taste, considering sodium chloride and lithium chloride the exemplary salty compounds [20]. Because $\mathrm{ENaC}$ functions as a sodium transepithelial transporter in many tissues such as the kidney or the lungs, this ion channel is expressed in many epithelial tissues. Thus, its simple existence in the GI does not help to consider the taste-like function of sodium salts throughout the alimentary canal and this is the reason for there being no studies on salt sensing in the GI. About sour taste, although a number of contenders have been suggested as sour taste receptors, they are still being disputed $[1,19]$. Finally, there are other GPCR nutrient receptors that, although have been described in the taste tissue, their taste-specific qualities are still under investigation. They are receptors that can bind to a wide variety of amino acids such as the extracellular calcium-sensing receptor (CaSR), which has been linked to kokumi substances, calcium, and large aromatic amino acids, the GPCR family $\mathrm{C}$ subtype 6A (GPCR6A) that binds to basic amino acids, or the G protein-coupled protein 92 (GPR92) that binds to peptone and may be also involved in the perception of umami taste [4,21-23]. Interestingly, in GI cells, these receptors have been associated with the regulation of gastric secretion, control of satiation, and GI motility [4,24]. There are other nutrient receptors that have been described in oral and post-oral tissues such as the G proteincoupled receptor 120 (GPR120) and the free fatty acid receptors 1, 2, and 3 (FFAR1, FFAR2, FFAR3). GPR120 and FFARs bind to free fatty acids of different lengths. GPR120 and FFAR1 (a.k.a., GPR 40) have been considered candidates for the oro-sensory perception of fats [25].

\section{The significance of gut sensing via taste receptors}

Chemical sensing in the gut was first proposed in the 19th century by the Nobel price physiologist Ivan Pavlov through his nerve antenna theory in which he assumed that nerve endings were exposed to the chemical milieu of the luminal content $[11,26]$. Later on, Bayliss and Starling in 1902 observed that by applying protons at the duodenum, there was a robust secretion of pancreatic secretions and the response was not mediated by nerves but rather by a secreted compound [27]. This compound was named 'secretin' and later designated as a hormone. As such, secretin is an emissary that carries 
chemical information to the predetermined target through the blood. With time, it became clear that intestinal nerves did not project to the surface of the intestine, and the intestinal sensor cell theory arose in the 1970s due to Fujita and Kobayashi [28]. They suggested the presence of bipolar nutrient-sensing cells. These cells can interact with nutrients at the lumen thanks to having projections toward the surface of the stomach and intestine [29]. The view that is most accepted today considers that taste GPCRs are present in 'open' enteroendocrine and brush cells also known as chemosensory cells. The enteroendocrine cells are the ones that dispatch nutrient information via peptide hormones and bioactive amines to the corresponding organs either via endocrine or vagal pathways as shown in Figure $1[11,26]$. The binding of single amino acids such as L-glutamate, L-phenylalanine, L-tryptophan, L-arginine, or L-lysine to their corresponding GPCRs (T1Rs, mGluR1, CaSR, or GPRC6A) in the stomach regulates the secretion of gastric hormones such as serotonin, gastrin, somatostatin, and ghrelin, the only known hormone that enhances hunger [4,30,31]. In rats and dogs, glutamate in the stomach activates the nerve endings of the vagus nerve via serotonin and nitric oxide, which in turn enhances gastric secretion also through vagus nerve responses [32,33]. Vagal efferent fibers, the ones carrying information from the brain, release acetylcholine upon stimulation. This vagal neurotransmitter is a potent activator of the proton pump of parietal cells, the cells in charge of producing hydrochloric acid that is under the regulation of gastrin and somatostatin [24,34]. In the duodenum, long-chain fatty acids, peptides, amino acids, and bitter compounds can induce the release of cholecystokinin (CCK) from I cells. Glucagon-like peptide 1 (GLP-1) is secreted from L cells in the ileum with sugars, longchain fatty acids, amino acids, and also bitter compounds; whereas the di-peptide tyrosine-tyrosine (PYY) comes from the colon as a result of short-chain fatty acids [4]. These regulatory GI hormones can signal nutrient information to the brain because the projections of the vagus nerve that lie underneath the lining of the GI contain receptors for serotonin, CCK, GLP-1, and PYY (Figure 1) [11]. In the brain, centers such as the arcuate nucleolus of the hypothalamus or the limbic system integrate nutrient information to regulate food intake, body metabolism, and the reward system.

\section{Conclusion and perspectives}

With the mounting body of evidence for the function of nutrient receptors in oral, gastric, and intestinal lining as mediators of food signals, it is becoming clearer that food components hold information that goes beyond their caloric values. Single sugars, amino acids, or even free fatty acids are not only a fast source of energy because they do not require digestion but also they provide strong signals from receptors in the mouth and the stomach before digestion with pancreatic juices. Foods that

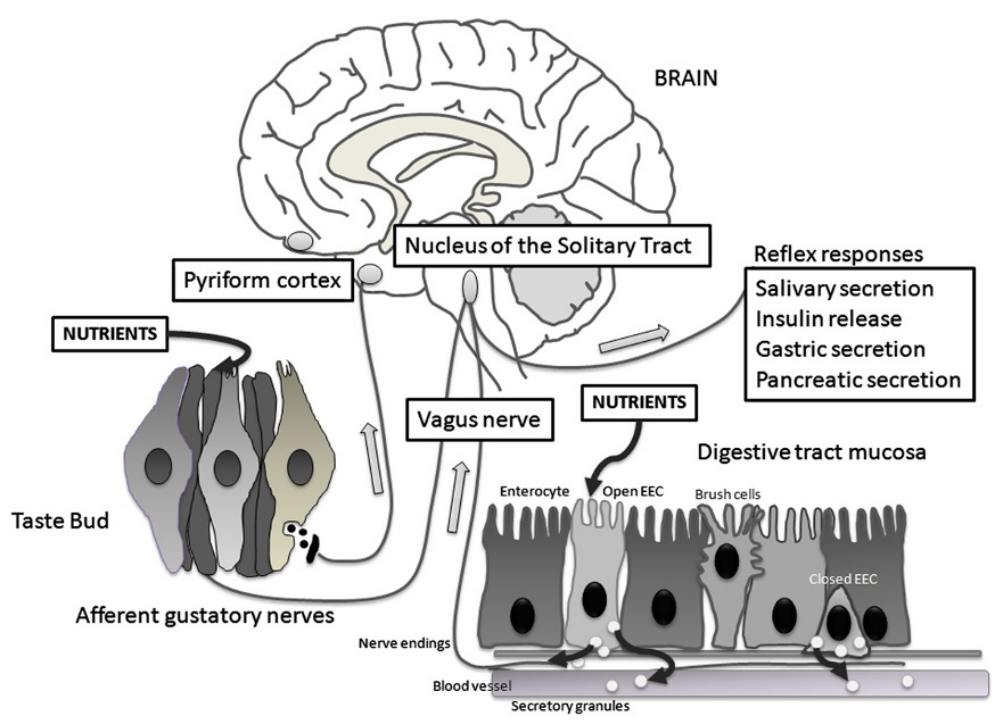

Figure 1 Schematic representation of the taste and gastrointestinal (GI) input. Schematic representation of the taste and gastrointestinal (Gl) input to the brain from the gustatory and vagus nerves, respectively. The gustatory system is represented by taste cells in onion-like taste buds and their gustatory nerves. Corresponding to the Gl system, there are two enteroendocrine cells (EEC), one that is open to the lumenreleasing cholecystokinin (CCK) and glucagon-like peptide 1 (GLP-1) in response to luminal nutrients and one that is closed. Vagal fibers are located underneath the Gl mucosa in close contact with hormone secretions. The signals from the gustatory system reach the rostral nucleus of the solitary tract whereas visceral impulses terminate at the caudal nucleus of the solitary tract. From the nucleus of the solitary tract, gustatory and visceral information projects to several brain regions including the amygdala, the hypothalamus, and the ventral posterior nucleus of the thalamus. These regions are involved with ingestive motivation, physiological reflexes, and energy homeostasis. 
are rich in free nutrients, such as either soup stocks or cured and fermented or aged meats and cheeses, offer clear gustatory and odorant cues. Having sharp taste and odorant sensorial experiences allows for more robust information to the brain, stronger learned anticipatory responses, and a better handling of nutrients in the body. This could be a key factor for a more efficient food intake regulation, which is a key to avoid overeating and overweight. More research is necessary for a better understanding of the integration of taste and visceral signals. This line of research may help better weight management in overweight adults and other metabolic diseases related to nutrient homeostasis in the body.

\section{Abbreviations \\ CaSR: calcium-sensing receptor; CCK: cholecystokinin; CPIR: cephalic phase insulin release; ENaC: epithelial sodium channel; FFARs: Free fatty acid receptors; Gl: gastrointestinal; GLP-1: glucagon-like peptide 1; GPCR6A: GPCR family C subtype 6A; GPR92: G protein-coupled protein 92; GPR40: G protein-coupled receptor 40; GPR120: G protein-coupled receptor 120; mGluR: metabotropic glutamate receptor.}

\section{Competing interests}

The author declares that she has no competing interests.

\section{Author's information}

Ana San Gabriel is the scientific affairs representative of the non-profit organization Umami Information Center.

\section{Acknowledgements}

This work has been supported by the Umami Information Center. The author is grateful for the support of Dr. Kumiko Ninomiya, director of the Umami Information Center, and Professor Ole Mouritsen Director of the MEMPHYSCenter for Biomembrane Physics at the University of Southern Denmark.

Their constant support has made this publication possible.

Received: 2 December 2014 Accepted: 2 December 2014

Published: 26 February 2015

\section{References}

1. Bachmanov A, Bosak NP, Lin C, Matsumoto I, Ohmoto M, Reed DR, Nelson TM: Genetics of taste receptors. Curr Pharm Des 2014, 20:2669-2683.

2. Spector A, Glendinning Jl: Linking peripheral taste processes to behavior. Curr Opin Neurobiol 2009, 19:370-377.

3. Teff KL: How neural mediation of anticipatory and compensatory insulin release helps us tolerate food. Physiol Behav 2011, 103:44-50.

4. Depoortere I: Taste receptors of the gut: emerging roles in health and disease. Gut 2014, 63:179-190.

5. Steiner J: What the Neonate Can Tell Us about Umami. New York: Marcel Dekker, Inc.; 1987.

6. Agostoni C, Carratu B, Boniglia C, Riva E, Sanzini E: Free amino acid content in standard infant formulas: comparison with human milk. J Am Coll Nutr 2000, 19:434-438.

7. Lönnerdal B: Effects of maternal dietary intake on human milk composition. J Nutr 1986, 116:499-513.

8. Beauchamp G, Mennella JA: Early flavor learning and its impact on later feeding behavior. J Pediatr Gastroenterol Nutr 2009, 48:S25-S30.

9. Sclafani A, Ackroff K: Role of gut nutrient sensing in stimulating appetite and conditioning food preferences. Am J Physiol Regul Integr Comp Physiol 2012, 302:R1119-R1133.

10. Laffitte A, Neiers F, Briand L: Functional roles of the sweet taste receptor in oral and extraoral tissues. Curr Opin Clin Nutr Metab Care 2014, 17:379-385.

11. Steinert $R$, Beglinger $C$ : Nutrient sensing in the gut: interactions between chemosensory cells, visceral afferents and the secretion of satiation peptides. Physiol Behav 2011, 105:62-70.

12. Margolskee R, Dyer J, Kokrashvili Z, Salmon KS, llegems E, Daly K, Maillet EL, Ninomiya Y, Mosinger B, Shirazi-Beechey SP: T1R3 and gustducin in gut sense sugars to regulate expression of $\mathrm{Na}+-$ glucose cotransporter 1 . Proc Natl Acad Sci U S A 2007, 104:15075-15080.

13. Adler E, Hoon MA, Mueller KL, Chandrashekar J, Ryba NJ, Zuker CS: A novel family of mammalian taste receptors. Cell 2000, 100:693-702.

14. Chandrashekar J, Mueller KL, Hoon MA, Adler E, Feng L, Guo W, Zuker CS, Ryba NJ: T2Rs function as bitter taste receptors. Cell 2000, 100:703-711.

15. Kawai M, Sekine-Hayakawa Y, Okiyama A, Ninomiya Y: Gustatory sensation of (L)- and (D)-amino acids in humans. Amino Acids 2012, 43:2349-2358.

16. Li X, Staszewski L, Xu H, Durick K, Zoller M, Adler E: Human receptors for sweet and umami taste. Proc Natl Acad Sci U S A 2002, 99:4692-4696.

17. San Gabriel A, Maekawa T, Uneyama H, Torii K: Metabotropic glutamate receptor type 1 in taste tissue. Am J Clin Nutr 2009, 90:743S-746S.

18. Chaudhari N, Landin AM, Roper SD: A metabotropic glutamate receptor variant functions as a taste receptor. Nat Neurosci 2000, 3:113-119.

19. Behrens $M$, Meyerhof W: Gustatory and extragustatory functions of mammalian taste receptors. Physiol Behav 2011, 105:4-13.

20. Chandrashekar J, Kuhn C, Oka Y, Yarmolinsky DA, Hummler E, Ryba NJ, Zuker CS: The cells and peripheral representation of sodium taste in mice. Nature 2010, 464:297-301.

21. Haid D, Widmayer P, Voigt A, Chaudhari N, Boehm U, Breer H: Gustatory sensory cells express a receptor responsive to protein breakdown products (GPR92). Histochem Cell Biol 2013, 140:137-145.

22. San Gabriel A, Uneyama H, Maekawa T, Torii K: The calcium-sensing receptor in taste tissue. Biochem Biophys Res Commun 2009, 378:414-418.

23. Ohsu T, Amino Y, Nagasaki H, Yamanaka T, Takeshita S, Hatanaka T, Maruyama Y, Miyamura N, Eto Y: Involvement of the calcium-sensing receptor in human taste perception. J Biol Chem 2010, 285:1016-1022.

24. San Gabriel A, Uneyama H: Amino acid sensing in the gastrointestinal tract. Amino Acids 2013, 45:451-461.

25. Cartoni C, Yasumatsu K, Ohkuri T, Shigemura N, Yoshida R, Godinot N, le Coutre J, Ninomiya Y, Damak S: Taste preference for fatty acids is mediated by GPR40 and GPR120. J Neurosci 2010, 30:8376-8382.

26. Uneyama $\mathrm{H}$, Takeuchi $\mathrm{K}$ : New frontiers in gut nutrient sensor research-from taste physiology to gastroenterology: preface. J Pharmacol Sci 2010, 112:6-7.

27. Bayliss WMSE: The mechanism of pancreatic secretion. J Physiol 1902 28:325-353.

28. Fujita T, Kobayashi S: Structure and function of gut endocrine cells. Int Rev Cytol Suppl 1977, 6:187-233.

29. Höfer D, Asan E, Drenckhahn D: Chemosensory perception in the gut. News Physiol Sci 1999, 14:18-23.

30. Haid D, Jordan-Biegger C, Widmayer $P$, Breer $H$ : Receptors responsive to protein breakdown products in g-cells and d-cells of mouse, swine and human. Front Physiol 2012, 10:65.

31. Haid $D$, Widmayer $P$, Breer $\mathrm{H}$ : Nutrient sensing receptors in gastric endocrine cells. J Mol Histol 2011, 42:355-364.

32. Zolotarev V, Khropycheva R, Uneyama H, Torii K: Effect of free dietary glutamate on gastric secretion in dogs. Ann N Y Acad Sci 2009, 1170:87-90.

33. Uneyama H, Niijima A, San Gabriel A, Torii K: Luminal amino acid sensing in the rat gastric mucosa. Am J Physiol Gastrointest Liver Physiol 2006, 291:1163-1170.

34. Goo T, Akiba Y, Kaunitz JD: Mechanisms of intragastric pH sensing Curr Gastroenterol Rep 2010, 12:465-470.

doi:10.1186/2044-7248-4-14

Cite this article as: San Gabriel: Taste receptors in the gastrointestinal system. Flavour 2015 4:14. 